\title{
TRANSIÇÃO PARA A CIDADE PÓS-CARBÓNICA: UMA PROPOSTA DE MOBILIDADE SUSTENTÁVEL PARA VIZELA ${ }^{1}$
}

\author{
João MONTEIRO \\ Departamento de Geografia, Universidade do Minho \\ joao.miguel15@hotmail.com
}

\begin{abstract}
Resumo
Um dos grandes desafios das sociedades contemporâneas é o de conciliar desenvolvimento com sustentabilidade, tal como é preconizado pelos 17 Objetivos de Desenvolvimento Sustentável elencados na Agenda 2030. Nesta lógica, o desafio da mobilidade tem merecido particular atenção, pois o setor dos transportes constitui um dos mais relevantes fatores para a (in)sustentabilidade urbana com evidentes impactes negativos sobre o ambiente, a economia e a sociedade. Deste modo, urge encontrar novas formas de pensar e fazer cidade, tendo por base a tríade da sustentabilidade e num processo de transição da cidade contemporânea para a cidade pós-carbónica.

Face ao exposto, neste artigo é apresentado um projeto de mobilidade sustentável para o município de Vizela, denominado "Projeto Mobizela" e que consiste na proposta de pedonalização de parte do seu centro histórico e o desenho de uma rede ciclável, procurando traduzir um novo paradigma de mobilidade que se pretende introduzir neste território.

Para tal, recorreu-se a operações de análise espacial através da utilização dos Sistemas de Informação Geográfica (S.I.G.), no qual revelaram-se ser ferramentas essenciais no apoio à tomada de decisão no âmbito do planeamento estratégico. Assim, espera-se que este projeto se possa constituir como um contributo no processo de transição de tornar Vizela uma cidade mais Sustentável, mais Acessível, mais Segura, mais Atrativa e mais Saudável.
\end{abstract}

Palavras-chave: transição; mobilidade sustentável; Vizela; S.I.G.; Projeto Mobizela.

\begin{abstract}
One of the great challenges of contemporary societies is to reconcile development with sustainability, as advocated by the 17 Sustainable Development Objectives presents in Agenda 2030. In this logic, the challenge of mobility has deserved particular attention, because the transport sector is one of the more relevant factors for urban (in) sustainability with evident negative impacts on the environment, economy and society. In this way, it is urgent to find new ways of thinking and making city, based on the triad of sustainability and in a process of transition from the contemporary city to the post-carbonic city.

Therefore, this article presents a sustainable mobility project for the municipality of Vizela, called the "Mobizela Project", which consists of the proposed pedestrianization of part of its historical center and the design of a cycling network, seeking to demonstrate a new paradigm to be introduced in this territory.

To this end, were used spatial analysis operations through the use of Geographic Information Systems (G.I.S.), in which they proved to be essential tools to support strategic decision-making. Thus, this project is expected to be a contribution to the transition process of making Vizela a more sustainable, accessible, safer, attractive and healthier city.
\end{abstract}

Keywords: transition; sustainable mobility; Vizela; GI.S.; Mobizela Project.

\footnotetext{
${ }^{1}$ O presente artigo tem por base a dissertação defendida pelo autor, a 18/12/2017, intitulada "Projeto Mobizela: uma proposta de mobilidade sustentável para Vizela Cittaslow" (http://hdl.handle.net/1822/54640).
} 


\section{A Problemática}

Durante milénios que as cidades foram planeadas e desenhadas em função da capacidade de deslocação das pessoas, sendo a escala humana um princípio basilar do desenho urbano. Contudo, no último século e sobretudo nas últimas décadas, as necessidades de mobilidade aumentaram substancialmente com grandes modificações nos padrões de mobilidade e na própria morfologia urbana. A crescente urbanização da sociedade assente num tecido urbano cada vez mais difuso e fragmentado, assim como os novos ritmos de vida, fizeram com que a população tenha de realizar mais deslocações para satisfazer as suas necessidades diárias, com viagens mais longas, mais complexas e cada vez mais dependentes do transporte motorizado individual (BANISTER, 2008).

Verifica-se, assim, um "decisivo triunfo do automóvel", sendo o século XX considerado, indubitavelmente, como o "século dos carros" (ARUP, 2016: 17). SHELLER \& URRY (2000) consideram que os automóveis criaram verdadeiras "sociedades da automobilidade", indo ao encontro do antropólogo Manuel Ramos que defende o "fenómeno da automobilização das sociedades contemporâneas" (RAMOS, 2013: 185). Efetivamente, esta dependência automobilística fez com que as cidades começassem a ser pensadas e desenhadas para o automóvel (NEWMAN \& KENWORTHY, 2015). Neste sentido, o tradicional modelo de planeamento territorial produziu uma verdadeira cultura do automóvel, no qual DOMINGUES (2006) defende que o automóvel modificou drasticamente a forma de habitar o urbano.

Considera-se então que os automóveis têm, de certa forma, "colonizado o espaço da vida humana quotidiana" (ARUP, 2016: 17), subordinando outras formas de mobilidade (URRY, 2004). O tráfego não-motorizado, nomeadamente a deslocação pedonal e ciclável, tem sido desta forma constantemente marginalizado e excluído (MERRIMAN, 2009; NEWMAN \& KENWORTHY, 2015), o que provoca desequilíbrios desenvolvidos na construção social da rua (NORTON, 2008). Já nos anos 60 do século passado, críticos como Lewis Mumford, Jane Jacobs, William H. Whyte ou Jan Gehl começaram a questionar este domínio do carro na cidade, preocupados com o desprezo da escala humana no desenho urbano. O espaço urbano tem assim sofrido uma desumanização em prol de um planeamento que privilegia o veículo motorizado individual, o que acarreta uma série de impactes negativos que afetam não só a comunidade em geral, mas, também, o próprio individuo. Assim, vejamos.

O setor dos transportes é um dos mais dependentes dos combustíveis fósseis e um dos principais responsáveis pela emissão de dióxido de carbono e de outros gases poluentes. Segundo dados do último Relatório do Estado do Ambiente, o setor dos transportes, fortemente dominado pelo tráfego rodoviário, representava em 2015 , cerca de $24 \%$ do total das emissões nacionais, superior à média europeia que se situava nos $21 \%$ (A.P.A., 2018). Importa destacar a estratégia europeia de descarbonização da sociedade, concretamente a nova revisão do Livro Branco, que sublinha a necessidade de se reduzir em 60\% as emissões de gases com efeito de estufa até 2050 (C.E., 2011).

Do ponto de vista da eficiência do sistema de transporte, os modos suaves são os meios de transporte mais rápidos e ajustados às necessidades de deslocações em meio urbano, uma vez que $50 \%$ destas deslocações são inferiores a 5 km (C.E., 2000). Além disso, a Comissão Europeia 
considera que os congestionamentos rodoviários são um dos maiores problemas urbanos atuais, refletindo-se em perdas anuais perto dos 100 mil milhões de euros, isto é, $1 \%$ do PIB da União Europeia (C.E., 2016).

É igualmente pertinente verificar alguns dos principais impactes do tráfego automóvel ao nível da saúde. Um estudo recentemente publicado, realizado no Reino Unido e com uma amostra de 263 450 pessoas, demonstrou que as pessoas que se deslocam frequentemente de bicicleta ou a pé para o trabalho apresentam um risco inferior de falecer devido a doenças cardíacas do que aqueles que se deslocam de automóvel ou transporte público: menos $52 \%$ para os ciclistas e menos $36 \%$ para os pedestres (CELIS-MORALES ET AL., 2017). Por outro lado, a O.M.S. considera mesmo que a poluição do ar representa o maior risco ambiental para a saúde pública, causando cerca de 3 milhões de mortes prematuras por ano (O.M.S., 2016). Só em Portugal, 6630 pessoas terão morrido prematuramente em 2015 devido à má qualidade do ar (A.E.A., 2017). Ora, se a poluição atmosférica é o principal problema para a saúde pública, a O.M.S. considera que o ruído é o segundo mais prejudicial, sendo que o tráfego automóvel constitui a principal fonte de ruído na urbe (C.E., 2016). Segundo um relatório da Agência Europeia do Ambiente, cerca de 125 milhões de pessoas estão expostas a níveis elevados de ruído, sendo a causa de mais de 900 mil casos de hipertensão, 43 mil hospitalizações e 10 mil mortes prematuras (A.E.A., 2014).

Neste sentido, deve-se contribuir para uma efetiva mudança de paradigma de mobilidade, invertendo a noção presente da pirâmide modal, sendo que os modos suaves, como andar a pé ou de bicicleta, devem ser privilegiados em detrimento do transporte motorizado individual. De acordo com o arquiteto e urbanista Jan Gehl, no seu livro "Cidades para Pessoas", depois de décadas de negligência com a dimensão humana e de se conhecerem os malefícios provenientes de uma mobilidade insustentável, agora, no início do séc. XXI, existe a necessidade e a vontade de se criar cidades vivas, seguras, sustentáveis e saudáveis, isto é, verdadeiras cidades para pessoas (GEHL, 2013). Verifica-se então uma forte tendência de humanização da cidade no planeamento urbano contemporâneo (BOARETO, 2010), no qual as diretrizes internacionais apelam a uma redução na dependência do uso do automóvel e o foco noutros meios de transporte mais sustentáveis. De forma a ultrapassar este desafio, a nova cultura de mobilidade suave tem de ser, necessariamente, acompanhada por um novo desenho do espaço urbano e pela construção de cidades (mais) caminháveis e cicláveis (GEHL, 2013).

\section{O território}

O município de Vizela localiza-se na N.U.T.S. II do Norte de Portugal Continental, mais precisamente na N.U.T.S. III do Ave, com uma área de apenas $24,7 \mathrm{~km}^{2}$ (o $7^{\circ}$ município mais pequeno de Portugal). À semelhança do noroeste português, e em particular da sub-região do Ave, Vizela caracteriza-se por um modelo territorial difuso e disperso, assente numa plurifuncionalidade do uso do solo (indústria, comércio, agricultura, serviços e habitação) e numa estreita ligação com o processo de industrialização patente neste espaço geográfico (CANTEIRO, 2005). 
Segundo dados do Instituto Nacional de Estatística (I.N.E., 2011), o município de Vizela contabilizava, em 2011, 23736 habitantes, apresentando a maior taxa de variação populacional do Ave, com uma variação positiva de 18,6\%, no período entre 1991 e 2011. Além disso, Vizela registava, em 2011, uma densidade populacional de 961 hab./ $\mathrm{km}^{2}$, muito superior à média subregional (411 hab. $\left./ \mathrm{km}^{2}\right)$, regional (173 hab. $\left./ \mathrm{km}^{2}\right)$ e nacional (115 hab./ $\left.\mathrm{km}^{2}\right)$. Destaque ainda para o facto de Vizela apresentar uma estrutura etária bastante jovem, sendo que $37 \%$ da sua população residente tinha menos de 25 anos, em 2011.

As características naturais de um dado território, nomeadamente a orografia e o clima, são fatores determinantes na implementação de uma estratégia de mobilidade sustentável, na medida em que estes podem incentivar ou desincentivar a utilização dos modos suaves. Em Vizela, verifica-se que $21 \%$ do seu território está associado a áreas com declives pouco acentuados (inferiores a $8 \%$ ) localizando-se junto aos principais cursos de água (Rio Vizela) e no núcleo urbano central. Em termos climáticos, Vizela insere-se numa região com afinidades mediterrâneas, mas com forte influência atlântica, o que se traduz num clima de temperaturas amenas, com pequenas amplitudes térmicas e forte pluviosidade média. Este facto demonstra que Vizela apresenta características naturais que são favoráveis à utilização da bicicleta e andar a pé.

No que diz respeito aos padrões de mobilidade, importa realizar uma análise à evolução da repartição modal entre 2001 e 2011. Desta forma, a partir da análise à Fig. 1 é possível retirar-se algumas conclusões que são transversais tanto a Vizela como no seu contexto supra-municipal.

Primeiramente, verifica-se uma diminuição generalizada do uso do transporte público. Esta diminuição foi mais expressiva em Vizela $(-4,4 \%)$, do que no Ave $(-3,4 \%)$, no Norte $(-3,1 \%)$ e em Portugal $(-3,2 \%)$. Este facto é bastante negativo uma vez que poderá colocar questões de viabilidade e sustentabilidade económica do serviço de transporte coletivo associados a uma baixa procura, levando assim a dificuldades acrescidas na definição de serviços regulares de transporte público. Em segundo lugar, à semelhança do que ocorre noutras escalas territoriais, o município Vizela regista igualmente uma perda de expressão dos modos suaves, ou seja, do modo pedonal e do modo ciclável. Apesar dos valores do uso da bicicleta estarem agregados aos do uso do motociclo, é sabido que, em 2011, o uso da bicicleta nas deslocações pendulares não ultrapassava os $0,5 \%$ no caso de Portugal, sendo que em Vizela estes valores são ainda mais residuais $(0,1 \%)$. No caso do modo pedonal, verifica-se também um decréscimo em todas as escalas analisadas, sendo que o caso de Vizela é bastante preocupante, uma vez que num período de apenas dez anos, a população que se desloca a pé nas suas viagens pendulares, reduziu drasticamente em um terço. Se em 2001 era o meio de transporte preferido (39\%), em 2011, este valor era de apenas $26 \%$. A terceira conclusão que se pode retirar e que está intrinsecamente relacionada com as anteriores, prende-se com o facto de existir um predomínio crescente das deslocações em automóvel. Entre 2001 e 2011, verificou-se um aumento considerável em Portugal $(+16,2 \%)$, no Norte $(+18,3 \%)$ e no Ave $(+20,9 \%)$. No caso de Vizela este aumento foi ainda mais acentuado, com um acréscimo de cerca de $23,3 \%$ e passando a ser o meio de transporte mais utilizado nas deslocações pendulares dos vizelenses em 2011 (57\%). 


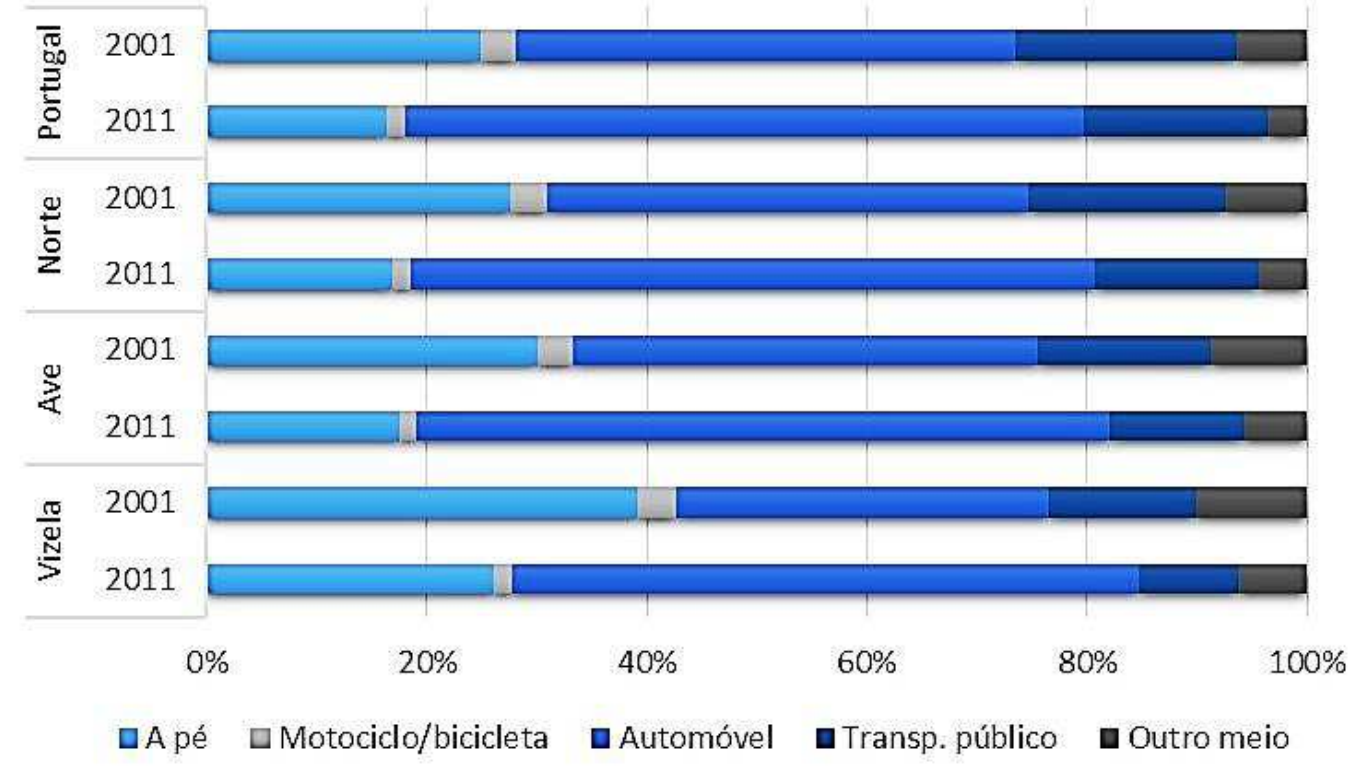

Figura 1 - Evolução da repartição modal, por escala territorial, entre 2001 e 2011.

Face ao exposto, verifica-se que as principais características da evolução da repartição modal centram-se, sobretudo, ao nível da diminuição do transporte público, da perda de expressão dos modos suaves e do predomínio crescente das deslocações em automóvel. Estes factos vêm reforçar a ideia do fenómeno da automobilização das sociedades contemporâneas defendida pela comunidade científica, com os consequentes impactes que este tipo de mobilidade acarreta consigo. Desta forma, torna-se necessário a adoção de medidas com vista a uma mudança no paradigma da mobilidade sustentável através de uma transferência modal (modal shift) em torno dos modos suaves.

\section{O Projeto}

Durante as últimas décadas, Vizela, em paralelo com grande parte da realidade internacional e nacional, foi continuamente desenhada e planeada quase exclusivamente em função do automóvel. Este mono-planeamento em torno do veículo motorizado individual marginalizou outras formas de mobilidade, sobretudo os modos suaves, retirando-lhes o seu espaço e contribuindo para um processo de desumanização da cidade. Além disso, a massificação do automóvel contribuiu para uma degradação da qualidade do ambiente natural e urbano com efeitos nefastos a múltiplas dimensões.

Contrariando essa estratégia do passado, o denominado "Projeto Mobizela" procura traduzir um novo paradigma de mobilidade que se pretende introduzir neste território e assenta num princípio de devolução da cidade de Vizela e dos seus espaços públicos às pessoas que nela habitam, estudam, trabalham ou visitam. Para isso, propõe-se a pedonalização de parte do centro histórico de Vizela e o desenho de uma vasta rede ciclável, no sentido de existir uma efetiva transferência modal do automóvel para o peão e para a bicicleta e de contribuir para uma partilha mais equitativa e 
democrática do espaço público. Deste modo, pretende-se construir uma verdadeira cidade para pessoas, sendo que a preocupação com a escala humana e a qualidade de vida deve ser uma constante ao longo deste processo, tornando Vizela uma cidade + Sustentável, + Acessível, + Segura, + Atrativa e + Saudável (S.A.S.A.S.). O nome "Mobizela" deriva da tentativa de agrupar o conceito de mobilidade com o território em que vai incidir este projeto, dando origem a um termo original, curto, de fácil compreensão e fácil de recordar, tal como o exemplo "MobiCascais".

Relativamente aos procedimentos metodológicos, nas últimas décadas tem-se verificado uma crescente aplicação dos Sistemas de Informação Geográfica (S.I.G.) ao nível do planeamento e do ordenamento do território, estando intrínsecamente associados à análise territorial dos sistemas de transportes. Neste sentido, efetuaram-se operações de análise espacial e modelação, tendo-se recorrido a ferramentas de análise de redes como as Áreas de Serviço e a Matriz de Origem/Destino. Importa salientar que optou-se por desagregar a informação ao nível do edificado, evitando assim possíveis "vazios demográficos" e enviesamentos na distribuição da população por subsecção e tornar a análise mais próxima da realidade.

\section{1- Proposta de pedonalização}

O município de Vizela, apesar de apresentar um modelo urbanístico disperso, possui um centro urbano relativamente consolidado, com uma grande oferta e diversidade de equipamentos que geram importantes fluxos pedonais. A Fig. 2 representa a distribuição dos principais equipamentos no centro urbano de Vizela e o seu acesso pedonal, no qual é possível observar que existe uma grande concentração de equipamentos num raio de 500 e 1000 metros e que estes estão perfeitamente acessíveis através de curtas deslocações pedonais. Este é um aspeto bastante positivo na implementação de um projeto de mobilidade sustentável, uma vez que é preciso recordar o grande potencial que o modo pedonal tem nas deslocações urbanas de menor distância.

No entanto, a crescente e exagerada utilização do automóvel nas deslocações diárias tem contribuído para uma imagem caótica e desordenada em alguns pontos da cidade de Vizela. Esta problemática verifica-se sobretudo no centro histórico, onde a pressão do automóvel proporciona um agravamento da poluição atmosférica e sonora e origina constrangimentos em termos de circulação e congestionamento. Além disso, a excessiva presença do veículo motorizado individual nesta área sensível contribui para uma progressiva deterioração das condições de walkability. Embora o modo pedonal possua uma grande expressão na repartição modal, pelo facto de que, aproximadamente, um em cada quatro vizelenses deslocar-se a pé nas suas viagens pendulares, a rede de percursos pedonais apresenta algumas deficiências. De acordo com um levantamento efetuado em 2011 sobre as condições de acessibilidade no núcleo urbano de Vizela, verificou-se que $10 \%$ das ruas não possuem passeios e que cerca de $15 \%$ dos passeios existentes possuem uma largura inferior àquela exigida por lei (C.M.V., 2011). Ora, tais valores representam um desafio no que diz respeito à acessibilidade e à segurança da circulação pedonal, contribuindo diretamente para a formação da "cidade das imobilidades" tal como é defendido por TELES (2014). Adicionalmente, verificam-se 
outros constrangimentos como a existência de barreiras arquitetónicas/urbanísticas (e.g. árvores, degraus/escadas, candeeiros ou postes de iluminação) que interrompem o percurso pedonal e uma certa "anarquia" da ocupação do espaço público pelos automobilistas através do estacionamento abusivo e ilegal.
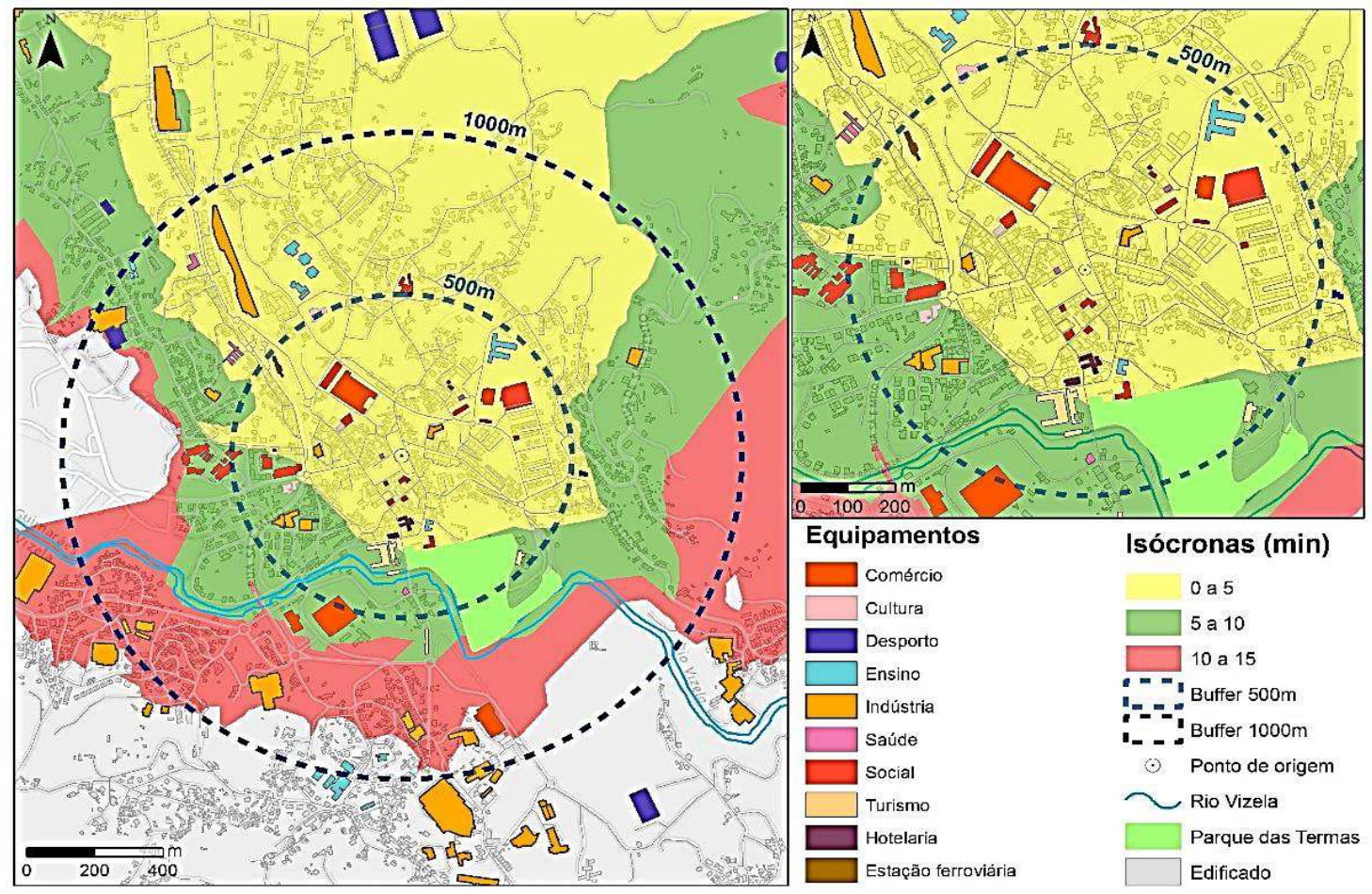

Figura 2 - Acesso pedonal aos principais equipamentos localizados no centro urbano de Vizela.

Neste sentido, propõe-se a pedonalização de parte do centro histórico de Vizela através da remoção da circulação motorizada em determinadas ruas. Assim, a criação de uma ampla área pedonal permitirá obter uma série de benefícios para a manutenção da qualidade do ambiente urbano. Desde logo, com a remoção do tráfego automóvel, as emissões de gases poluentes e os níveis de ruído irão baixar significativamente, o que irá contribuir para uma melhoria da qualidade do ar e, principalmente, da qualidade de vida dos cidadãos. Além disso, existirá um aumento da segurança na usufruição destes espaços através da redução do número de conflitos entre os pedestres e os veículos. Outro fator extremamente positivo que a possível área pedonal trará, é ao nível da atratividade que o centro ganhará, através de um renovado espaço público que seja convidativo e que atraia as pessoas de volta a este local, com uma consequentemente maior dinamização económica. Desta forma, Vizela verá o seu património valorizado, com um centro urbano atrativo e vibrante, envolvendo a comunidade ao mesmo tempo que estimula a atividade económica.

A Fig. 3 apresenta a proposta para a pedonalização de parte do centro histórico de Vizela que aproveita os espaços pedonais da Praça da República e do Jardim Público Manuel Faria e que, na sua fase final, irá abranger uma área total de mais de $15 \mathrm{mil} \mathrm{m}^{2}$. Sugere-se que este seja um 
processo gradual e faseado, por forma a que a cidade e a própria população se possa adaptar a esta nova realidade e reconhecer as suas vantagens associadas a esta medida, aumentando assim o seu grau de aceitação. Salienta-se que nem todas as ruas podem ser exclusivamente pedonais, sendo necessário garantir o acesso aos moradores locais e aos comerciantes para cargas e descargas.
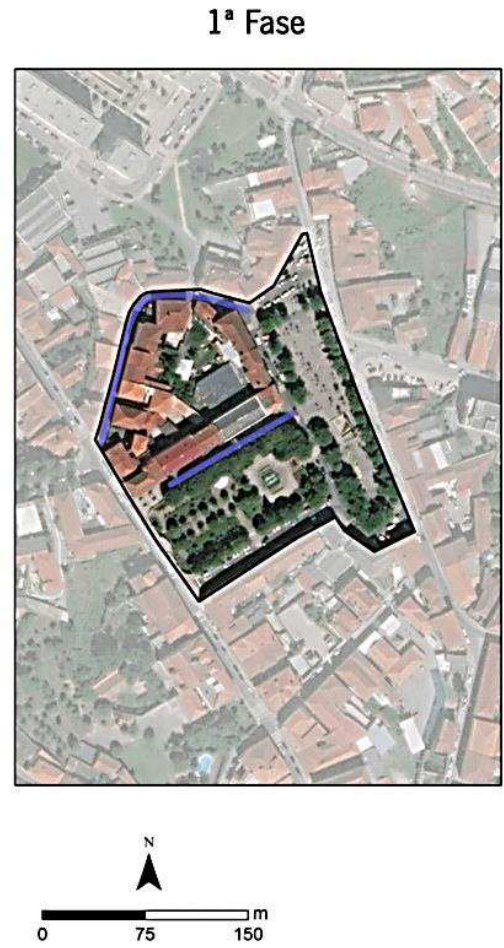

$2^{\mathrm{a}}$ Fase
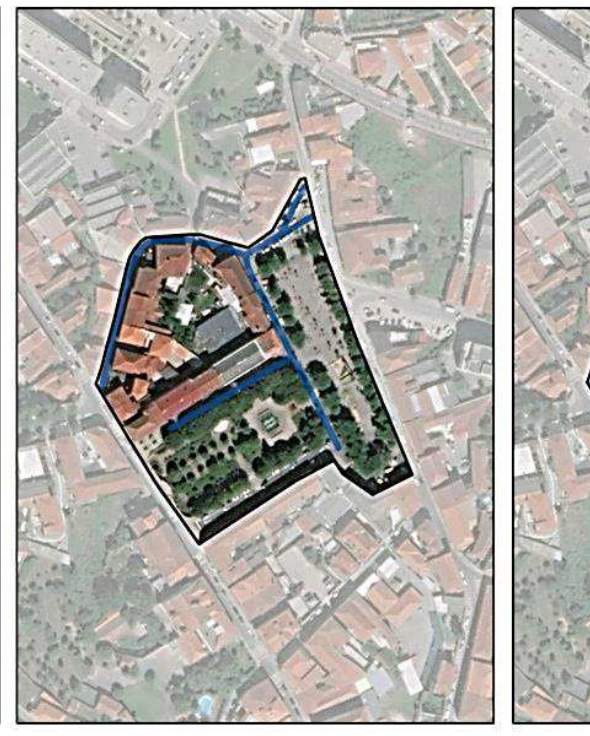

Figura 3 - Fases da proposta de pedonalização.

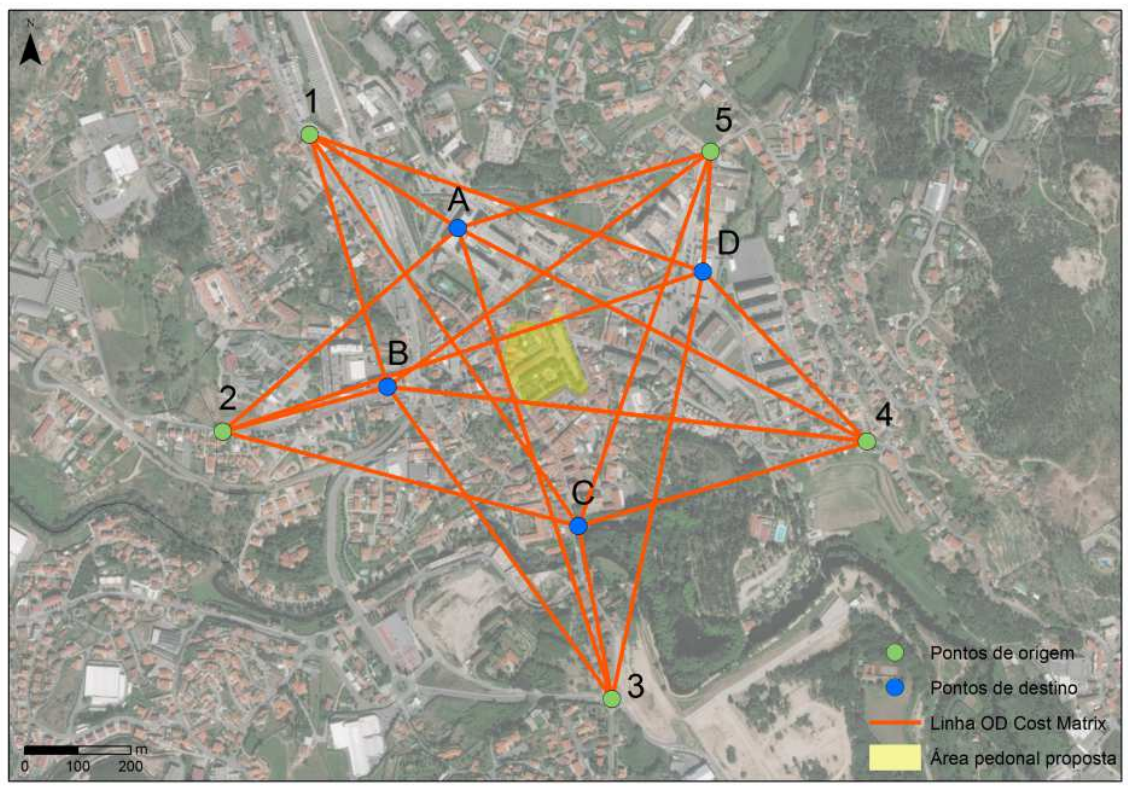

Figura 4 - Localização dos pontos da Matriz Origem/Destino 
Um dos maiores obstáculos num projeto de pedonalização de uma determinada área é o receio de que a medida resulte num aumento da distância e dos tempos de viagem da circulação automóvel. Para isso, realizou-se uma análise Matriz Origem/Destino no qual escolheram-se, como pontos de origem, cinco pontos periféricos e de entrada no núcleo central de Vizela $(1,2,3,4,5)$ e, como pontos de destino, quatro dos principais equipamentos: Câmara Municipal (A), Bombeiros (B), entrada principal do Parque das Termas (C) e Mercado (D) (Fig. 4). Desta forma, torna-se possível comparar cenários com o objetivo de avaliar qual o impacte que a área pedonal proposta poderá vir a ter. Os valores destes cenários (antes e depois da pedonalização) encontram-se expostos na Tabela I. Numa breve análise, constata-se que a proposta de implementação de uma área pedonal no centro histórico de Vizela não trará significativos impactes na circulação automóvel.

Tabela I - Resultados da Matriz Origem/Destino em termos de tempo (minutos)

\begin{tabular}{c|cc|cc|cc|cc}
\hline \multirow{2}{*}{$\begin{array}{c}\text { Pontos de } \\
\text { Origem }\end{array}$} & \multicolumn{7}{|c|}{ Pontos de Destino } \\
\cline { 2 - 9 } & \multicolumn{2}{|c|}{ A } & \multicolumn{2}{|c}{ B } & \multicolumn{2}{c}{ C } & \multicolumn{3}{c}{ D } \\
\cline { 2 - 9 } & Antes & Depois & Antes & Depois & Antes & Depois & Antes & Depois \\
\hline 1 & 0,32 & 0,32 & 0,43 & 0,43 & 1,17 & 1,17 & 1,12 & 1,12 \\
2 & 1,02 & 1,02 & 0,23 & 0,23 & 1,05 & 1,05 & 1,33 & 1,43 \\
3 & 1,19 & 1,19 & 0,49 & 0,49 & 0,24 & 0,24 & 1,41 & 1,41 \\
4 & 1,19 & 1,19 & 1,40 & 1,50 & 1,19 & 1,19 & 0,45 & 0,45 \\
5 & 0,59 & 0,59 & 1,26 & 1,36 & 1,33 & 1,33 & 0,17 & 0,17 \\
\hline
\end{tabular}

Fonte: Elaboração própria

\section{2- Proposta de rede ciclável}

A única infraestrutura ciclável existente no município de Vizela localiza-se na margem esquerda do Rio Vizela, junto ao Parque das Termas. Esta foi inaugurada em 2012, no âmbito da reabilitação da margem ribeirinha do Rio Vizela e é utilizada apenas para fins recreativos e de lazer. Possui uma dimensão residual (pouco mais de $1 \mathrm{~km}$ de extensão), sendo claramente insuficiente para servir de forma eficiente a população vizelense. Verifica-se então que existe a necessidade de implantação de uma rede ciclável que deverá responder tanto às necessidades lúdicas como às necessidades de deslocação diária, uma rede que funcionará como um estímulo à utilização da bicicleta em detrimento do automóvel, com claros benefícios em termos ambientais, económicos e sociais. Neste sentido, com o Projeto Mobizela propõe-se a construção de uma extensa rede ciclável que seja coesa e funcional com uma extensão total de $27,7 \mathrm{~km}$ distribuídos não só pelo centro urbano, mas também pelas restantes freguesias que compõem o território de Vizela (Fig. 5). Adicionalmente, sugere-se uma possível expansão desta rede para os municípios vizinhos, designadamente Felgueiras, 
Lousada, Guimarães e Santo Tirso, por forma a aumentar a sua área de influência e o seu número de utilizadores. Desta forma, a bicicleta poderá ser utilizada como meio de transporte nas intensas deslocações pendulares intermunicipais que se verificam entre estes territórios.

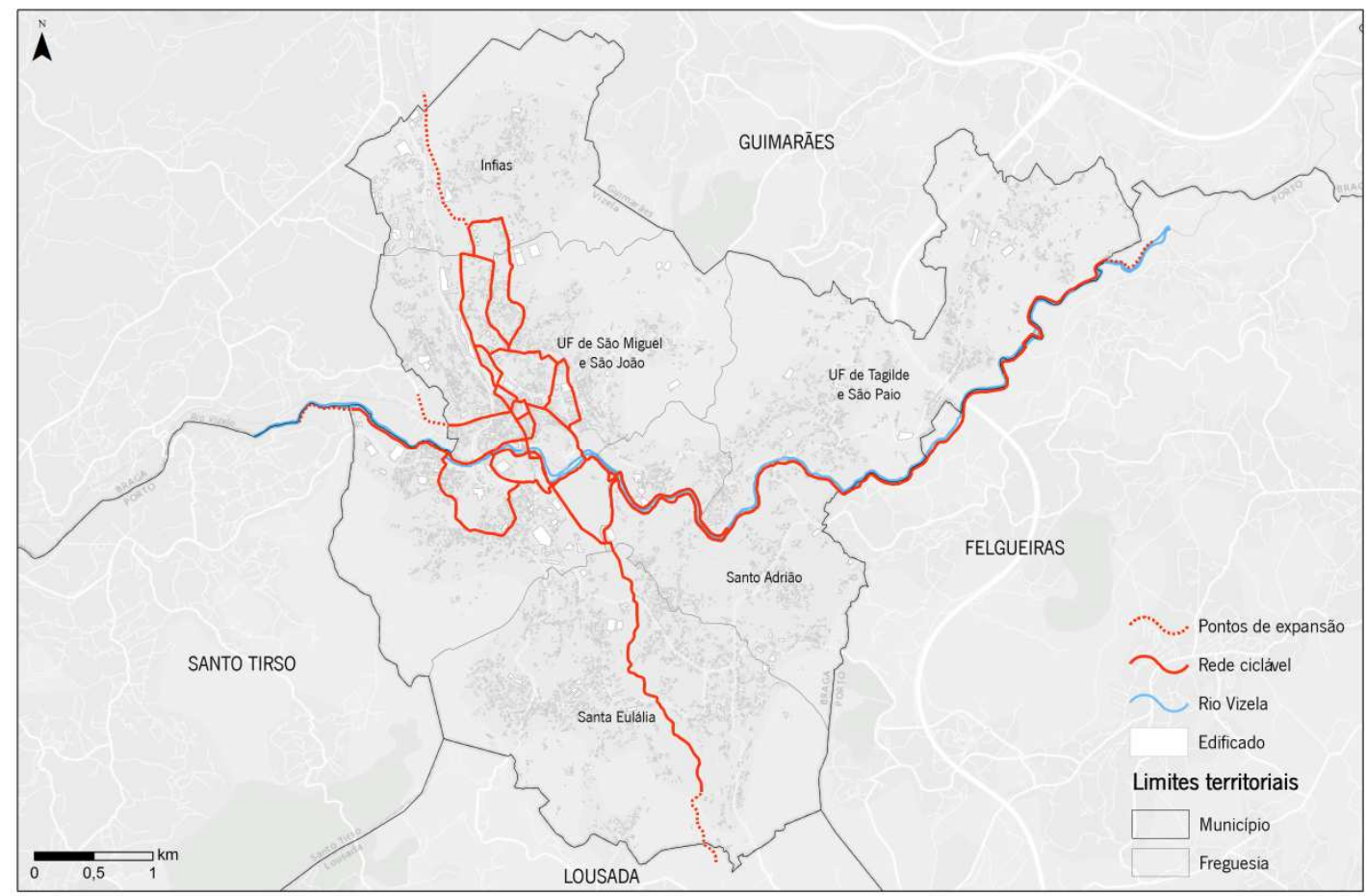

Figura 5 - Rede ciclável proposta.

De acordo com os princípios que emanam do conceito de bikeability, uma rede ciclável deve possuir uma grande cobertura territorial e oferecer ligações contínuas, diretas e seguras aos principais polos geradores de tráfego, como equipamentos públicos, áreas residenciais, áreas comerciais ou pontos de lazer. Desta forma, a rede ciclável proposta abrangerá 13296 habitantes, ou seja, aproximadamente $56 \%$ da população residente de Vizela estará a menos de 300 metros de uma infraestrutura ciclável (Fig. 6).

Paralelamente, um dos pontos mais importantes na conceção de uma rede ciclável é a sua ligação aos principais polos geradores de tráfego uma vez que pode representar uma maior taxa de utilização. Através da Fig. 7 é possível constatar que a rede ciclável proposta abrange a maior parte destes equipamentos, estando acessíveis por bicicleta em deslocações até 15 min. Aliás, numa análise mais pormenorizada verifica-se que em deslocações com duração inferior ou igual a 5 minutos é possível aceder, a partir de um percurso ciclável, a uma série de equipamentos. 


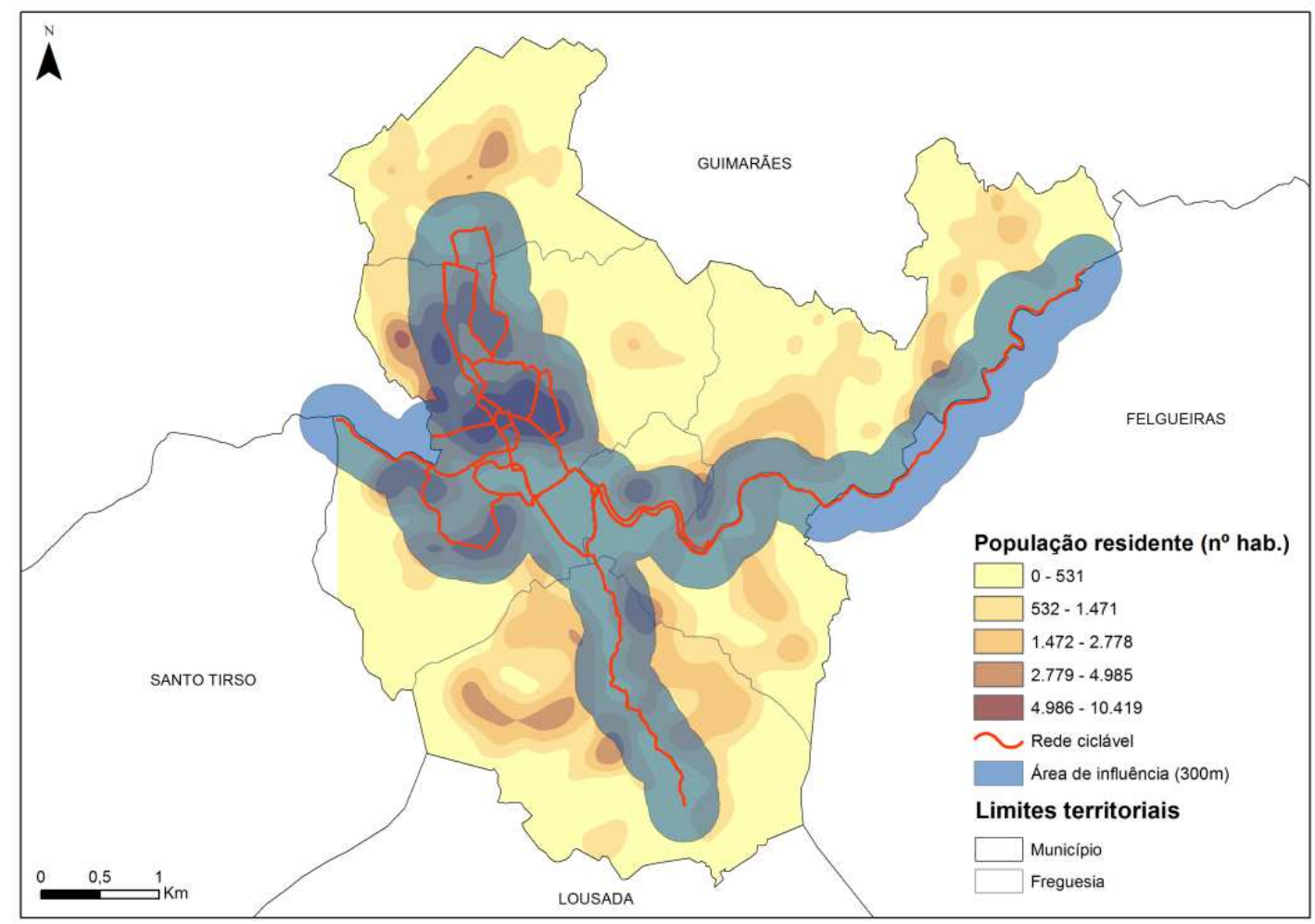

Figura 6 - Área de influência da rede ciclável proposta

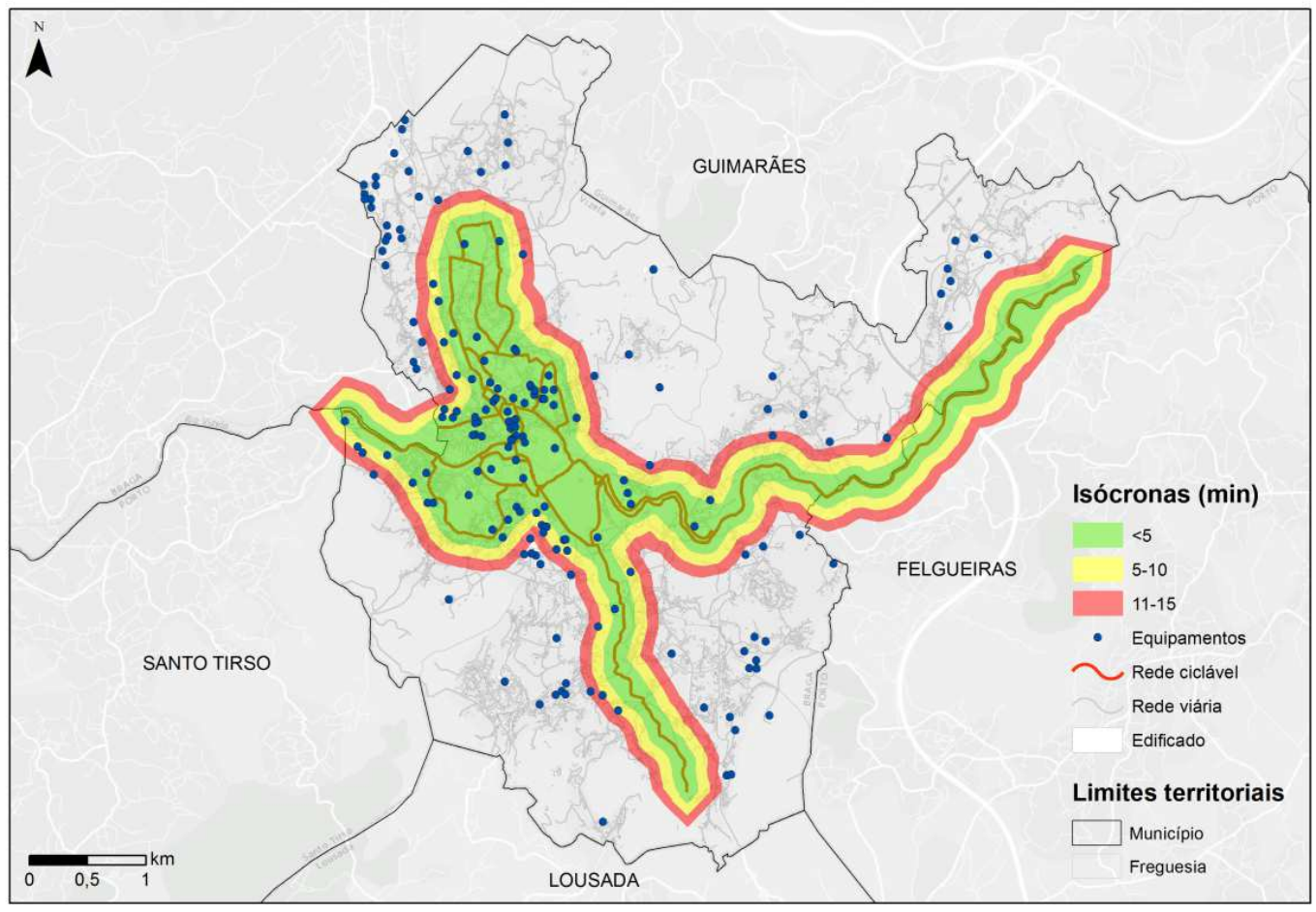

Figura 7 - Equipamentos abrangidos pela rede ciclável até 15 minutos de distância. 
No entanto, é importante dedicar uma análise mais centrada num outro equipamento que é considerado fundamental na implementação de uma estratégia de mobilidade sustentável: a escola. Deste modo, considerou-se todas as escolas básicas e secundárias do município de Vizela e verificou-se que a maior parte destas se localiza a menos de 15 minutos da rede ciclável (Fig. 8).

Ao cruzar esta informação com os dados populacionais, constata-se que $55,3 \%$ da população vizelense se insere neste intervalo temporal de $15 \mathrm{~min}$., sendo que $30,2 \%$ se encontra até 5 minutos de distância. Porém, é necessário efetuar esta análise a um segmento populacional mais restrito, designadamente ao da população com idade compreendida entre os 10 e os 19 anos, uma vez que são estes quem serão os principais utilizadores dos percursos cicláveis para as deslocações a estes equipamentos. Assim, verifica-se que $53,2 \%$ dos habitantes entre os 10 e os 19 anos de idade estão a menos de 15 minutos de uma escola a partir da rede ciclável proposta e pouco mais de $1 / 4(28,3 \%)$ a menos de 5 minutos de distância (Fig. 9).

Desta forma, uma grande parte dos percursos casa-escola podem ser realizados com recurso à bicicleta, no qual se deve promover a implementação de iniciativas cicláveis, como o Bike2school. É importante o incentivo desta camada mais jovem da população a adquirir estes hábitos de deslocação saudáveis, uma vez que, por um lado, são uma forma de combate ao sedentarismo e de promoção do desporto na população em idade escolar e, por outro, são determinantes para uma maior autonomia dos mais jovens.

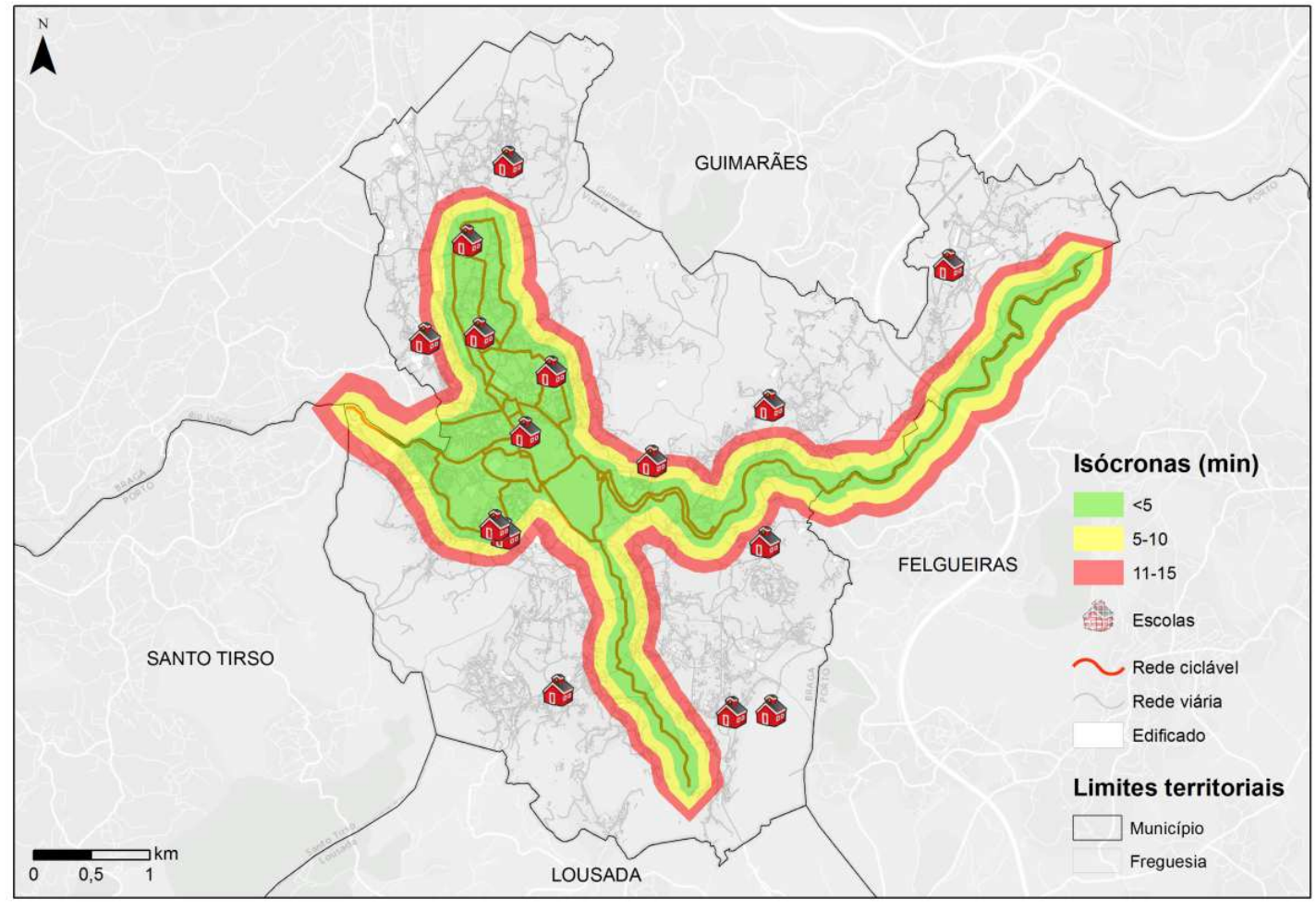

Figura 8 - Escolas abrangidas pela rede ciclável 


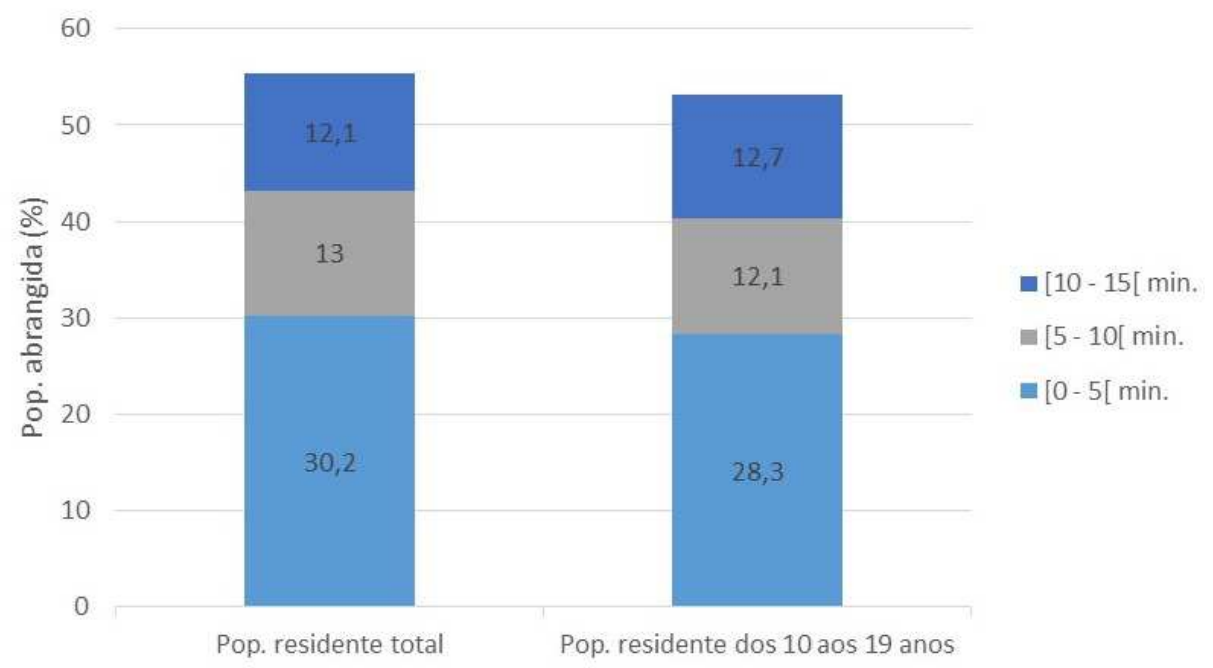

Figura 9 - População (total e dos 10-19 anos) abrangida pela rede ciclável e até 15 min. de uma escola.

\section{Considerações finais}

A mobilidade sustentável é cada vez mais uma prioridade de quem gere as nossas cidades e os nossos territórios, sendo necessário implementar estratégias e projetos neste âmbito. A Comissão Europeia assim como a comunidade científica têm constantemente alertado para os impactes nocivos que o tradicional mono-planeamento em torno do automóvel tem causado no ambiente, na economia e na sociedade. Neste sentido, verifica-se que existe uma evidente necessidade de se concretizar uma efetiva mudança do paradigma de mobilidade.

Para tal, é fundamental inverter a noção da pirâmide modal atual, no qual os modos de transportes mais sustentáveis, como o andar a pé e a bicicleta, devem ser privilegiados em detrimento do veículo motorizado. Saliente-se que não se trata de criar cidades onde não se possa andar de automóvel; trata-se sim, de criar uma cidade onde o automóvel é uma opção e não uma real necessidade. Desta forma, devem-se desenhar cidades mais caminháveis e mais cicláveis, no sentido de uma utilização mais racional do automóvel e, simultaneamente, garantir melhores condições de vida aos seus habitantes e visitantes.

Porém, não nos podemos basear exclusivamente no célebre princípio "constrói e eles virão". Assim, a aposta numa estratégia de mobilidade sustentável deve ser encarada como um investimento tanto ao nível da infraestrutura como ao nível das pessoas, no sentido de se alcançar uma verdadeira nova cultura de mobilidade. O maior desafio a ultrapassar reside pois na mudança de mentalidades e comportamentos, uma vez que através da compreensão e adesão das pessoas, sobretudo das camadas mais jovens, é que se conseguirá atingir o sucesso pretendido. Nesta lógica, é fundamental a realização de iniciativas de formação e sensibilização (e.g. Semana Europeia da Mobilidade, Dia Europeu sem Carros, Sexta de Bicicleta, Cycle Chic, Bike2school, EducaBicla, PediBus, entre outras), de modo a estimular uma maior utilização da bicicleta e andar a pé. Além disso, deve-se 
salientar um outro fator-chave que é crucial numa estratégia de mobilidade sustentável: a vontade política. A alteração do paradigma de mobilidade que as (so)ci(e)dades contemporâneas devem adotar depende, acima de tudo, da vontade dos seus decisores políticos, no qual os conceitos de descarbonização e de humanização são indissociáveis em prol de uma maior sustentabilidade e qualidade de vida da população.

\section{Bibliografia}

AGÊNCIA EUROPEIA DO AMBIENTE (2014). Noise in Europe. Luxemburgo: Serviço das Publicações Oficiais das Comunidades Europeias.

AGÊNCIA EUROPEIA DO AMBIENTE (2017). Air quaility in Europe. Luxemburgo: Serviço das Publicações Oficiais das Comunidades Europeias.

AGÊNCIA PORTUGUESA DO AMBIENTE (2018). Relatório do Estado do Ambiente. Lisboa: Agência Portuguesa do Ambiente.

ARUP (2016). Cities Alive - Towards a walking world. Londres: Arup.

BANISTER, D. (2008). The sustainable mobility paradigm. Transport Policy, 15, 73-80.

BOARETO, R. (2010). A bicicleta e as cidades: como inserir a bicicleta na política de mobilidade urbana. São Paulo: Instituto de Energia e Meio Ambiente.

CÂMARA MUNICIPAL DE VIZELA (2011). Plano de Soluções Integradas de Acessibilidade para Todos. Vizela.

CANTEIRO, E. (2005). Mortalidade Infantil e práticas associadas ao primeiro ano de vida - Um estudo no território de Vizela. Guimarães: Núcleo de Estudos de População e Sociedade da Universidade do Minho.

CELIS-MORALES, A., LYALL, D., WELSH, P., ANDERSON, J., STEELL, L. YIBING, G., MALDONADO, R., MACKAY, D., PELL, J., SATTAR, N. \& GILL, J. (2017). Association between active commuting and incident cardiovascular disease, cancer, and mortality: prospective cohort study. British Medical Journal, BMJ, 357: j1456.

COMISSÃO EUROPEIA (2000). Cidades para Bicicletas, Cidades de Futuro. Luxemburgo: Serviço das Publicações Oficiais das Comunidades Europeias.

COMISSÃO EUROPEIA (2011). White paper 2011: Roadmap to a single European transport area towards a competitive and resource efficient transport system. Luxemburgo: Serviço das Publicações Oficiais das Comunidades Europeias.

COMISSÃO EUROPEIA (2016). Estratégia Europeia de Mobilidade Hipocarbónica. Luxemburgo: Serviço das Publicações Oficiais das Comunidades Europeias.

DOMINGUES, A. (2006). Cidade e Democracia. 30 Anos de Transformação urbana em Portugal. Lisboa: Argumentum.

GEHL, J. (2013). Cidades para Pessoas. São Paulo: Perspectiva.

INSTITUTO NACIONAL DE ESTATíSTICA (2011). XV Recenseamento Geral da População e V Recenseamento Geral da Habitação - Resultados definitivos. Lisboa: Instituto Nacional de Estatística.

MERRIMAN, P. (2009). Automobility and the Geographies of the Car. Geography Compass, 3, 586599.

NEWMAN, P. \& KENWORTTHY, J. (2015). The End of Automobile Dependence. Washington: Island Press. 
NORTON, P. (2008). Fighting Traffic: The Dawn of the Motor Age in the American City. Massachusetts: Massachusetts Institute of Technology.

ORGANIZAÇÃO MUNDIAL DE SAÚDE (2016). Ambient air pollution: A global assessment of exposure and burden of disease. Genebra: OMS.

RAMOS, M. (2013). A automobilização do Pensamento Selvagem. Lisboa: ISCTE.

SHELLER, M. \& URRY, J. (2000). The city and the Car. International Journal of Urban and Regional Research, 24, 737-57.

TELES, P. (2014). A Cidade das (i)Mobilidades. Manual técnico de Acessibilidade e Mobilidade para Todos. Porto: MPT.

URRY, J. (2004). The 'system' of automobility. Theory, Culture, and Society, 21, 25-39. 